\title{
JUVENTUDE RURAL: ENTRE O PARTIR E O PERMANECER NO CAMPO. A DINÂMICA DOS JOVENS RURAIS DO MUNICÍPIO DE BELA VISTA DE GOIÁS (GOIÁS/BRASIL).
}

\author{
Lorrany dos Santos Ferreira ${ }^{1}$ \\ Andréa Vettorassi ${ }^{2}$
}

\section{RESUMO}

Este estudo se insere no conjunto de reflexões sobre a juventude, em especial, sobre aquela que reside no campo e estuda na cidade. O trabalho busca identificar e analisar as concepções de campo e de cidade dos jovens estudantes das escolas públicas do município de Bela Vista de Goiás, região metropolitana de Goiânia/Goiás, que, em meio a tantos dilemas sobre o futuro, ainda precisam optar entre permanecer no campo como integrante da agricultura familiar ou partir para a cidade em busca de outro modo de vida que corresponda às suas aspirações futuras. $O$ foco da pesquisa são os estudantes do Ensino Médio, exclusivamente aqueles entre a faixa etária de 15 a 24 anos, da escola Colégio Estadual Pedro Vieira Januário, cuja formação acontece em período integral. Assim, sendo uma escola de período integral, buscamos compreender como esses jovens estudantes participam de atividades ligadas ao campo e à cidade e, consequentemente, como sua identidade é construída. Partindo dessas considerações, a proposta metodológica é entrevistar os estudantes, a partir de um roteiro estruturado, sobre questões que abordam assuntos pessoais, econômicos, familiares, a perspectiva futura e o trabalho destes.

Palavras-chave: Juventude. Campo-cidade. Agricultura familiar.

\footnotetext{
${ }^{1}$ Mestranda em Sociologia pela Universidade Federal de Goiás. E-mail: ferreiralorrany@hotmail.com 2 Doutora em Sociologia professora na Universidade Federal de Goiás. E-mail: andreavettorassi@yahoo.com.br.
} 


\section{INTRODUÇÃO}

Pensar em juventude é associá-la a problemas. O termo "jovem" refere-se a uma fase entre a infância e a vida adulta, e nesse processo de transição que a identidade do indivíduo é formada. Sposito (2002) reconhece que a própria definição da categoria juventude aponta para um modo de passagem - heteronomia da criança para a autonomia de um adulto -, no entanto, a duração e suas características têm variado nos processos e formas, porque a estruturação das idades difere enormemente de uma sociedade a outra. Dessa forma, por ser uma etapa da vida que merece atenção, este estudo reflete sobre a questão de jovens do meio rural, mas jovens esses que dividem sua cultura entre dois espaços: o campo e cidade.

A proposta de trabalho surge de uma aproximação com jovens estudantes do ensino médio da rede estadual de ensino do município de Bela Vista de Goiás, região metropolitana de Goiânia - Goiás (Brasil), denominada Grande Goiânia, que assim como muitos jovens, migram diariamente do campo para a cidade a fim de concluírem o ensino médio. Esses jovens, além da terem preocupações próprias de sua fase, ainda precisam decidir se, após concluírem o ensino básico, devem buscar uma profissionalização (ou não) que os mantêm integrados à agricultura familiar ou se devem romper com a atividade camponesa e migrar para os centros urbanos a fim de mudarem sua realidade, buscando uma profissão que os levem a ascensão social.

Várias questões permeiam essa discussão, portanto, para que seja possível uma investigação sociológica desse evento, propomos compreender, especialmente, as razões do processo de migração entre o campo e a cidade praticada por estes jovens em questão. Para tanto, tomamos como objeto de pesquisa os alunos do Colégio Estadual Pedro Vieira Januário situado no município de Bela Vista de Goiás, em Goiás. O foco da pesquisa são os alunos, entre a faixa etária de 15 a 24 anos, que residem no campo, mas que precisam migrar diariamente para a cidade a fim de concluírem o ensino médio.

Além desses pontos levantados, os objetivos da pesquisam se ampliam em analisar as políticas públicas para os jovens rurais no município aqui mencionado; estudar os dados sobre a população rural, especialmente em relação aos jovens; 
compreender o imaginário da juventude rural, sobretudo sobre o futuro e suas perspectivas profissionais; Entender a relação do jovem com o campo e a cidade (identidade, lazer, trabalho, família, entre outros); e analisar a questão do gênero no campo, especialmente sobre a presença e/ou ausência da mulher.

\section{A CATEGORIA JUVENTUDE}

A palavra juventude tem assumido diferentes significados de acordo com o contexto histórico, social, econômico e cultural vigente. Porém, o sentido mais comumente encontrado é aquele que a define como uma fase de transição entre a adolescência e a vida adulta, um momento de preparação para um "devir", conforme analisam Dayrell e Gomes, comentando sobre as imagens atribuídas a essa fase da vida. "Uma das mais arraigadas é a juventude vista na sua condição de transitoriedade, onde o jovem é um 'vir a ser', tendo no futuro, na passagem para a vida adulta, o sentido das suas ações no presente" (Dayrell; Gomes, s/d, p.1).

Segundo a Organização Pan-Americana da Saúde, Organização Mundial da Saúde (OPS/OMS), juventude é uma categoria sociológica que representa um momento de preparação de sujeitos - jovens - para assumirem o papel de adulto na sociedade e abrange o período dos 15 aos 24 anos de idade. No Brasil, a atual Política Nacional de Juventude (PNJ), considera jovem todo cidadão ou cidadã da faixa etária entre os 15 e os 29 anos. A Política Nacional de Juventude divide essa faixa etária em três grupos: jovens da faixa etária de 15 a 17 anos, denominados jovens-adolescentes; jovens de 18 a 24 anos, como jovens-jovens; e jovens da faixa dos 25 a 29 anos, como jovens-adultos. Embora analisar o significado da palavra juventude possa ser um tema instigante, não se pretende aprofundar essa discussão neste momento da pesquisa.

Entretanto, em meio a tantas instabilidades, ações contraditórias, certezas e incertezas que o jovem se torna um adulto. Por ser uma fase de transição, um processo de passagem, o jovem carrega o fardo de ser uma representação do futuro, espera-se muito dele para mudar os rumos do país. Sendo assim, a experiência dos jovens é o fator propulsor da dinâmica da sociedade. E, muitas vezes, é o canal de 
introdução de mudanças na sociedade. As pessoas que se encontram vivendo a sua juventude são aquelas que movimentam novas ideias no meio em que vivem.

Entretanto, em meio a tantas instabilidades, ações contraditórias, certezas e incertezas que o jovem se torna um adulto. Por ser uma fase de transição, um processo de passagem, o jovem carrega o fardo de ser uma representação do futuro, espera-se muito dele para mudar os rumos do país. Sendo assim, a experiência dos jovens é o fator propulsor da dinâmica da sociedade. E, muitas vezes, é o canal de introdução de mudanças na sociedade. As pessoas que se encontram vivendo a sua juventude são aquelas que movimentam novas ideias no meio em que vivem.

\section{O MUNICÍPIO DE BELA VISTA DE GOIÁS E AS ESCOLAS ESTADUAIS DE NÍVEL MÉDIO: BREVES APONTAMENTOS}

O município de Bela Vista de Goiás está a $45 \mathrm{~km}$ da capital do estado de Goiás, a cidade de Goiânia. Entretanto, é considerado parte da região metropolitana de Goiânia, conhecida popularmente por Grande Goiânia, uma conurbação de cidades ao redor de Goiânia composta por vinte municípios. A cidade de Bela Vista de Goiás está situada na região centro-oeste do país, sua população é de, aproximadamente, 28077 habitantes (IBGE, 2016). O município foi fundando em 1896. Segundo a narrativa local, a cidade surgiu próxima aos centros de mineração, onde tropeiros e carreiros que transportavam mercadorias do estado de Minas Gerais para a estado de Goiás, fizeram do local ponto de pouso e de "rancho dos tropeiros", assim circundando-o surgiu o povoado que, tempos depois, em 5 de junho de 1896, foi elevado à categoria de cidade. 
Localização de Bela Vista de Goiás em Goiás

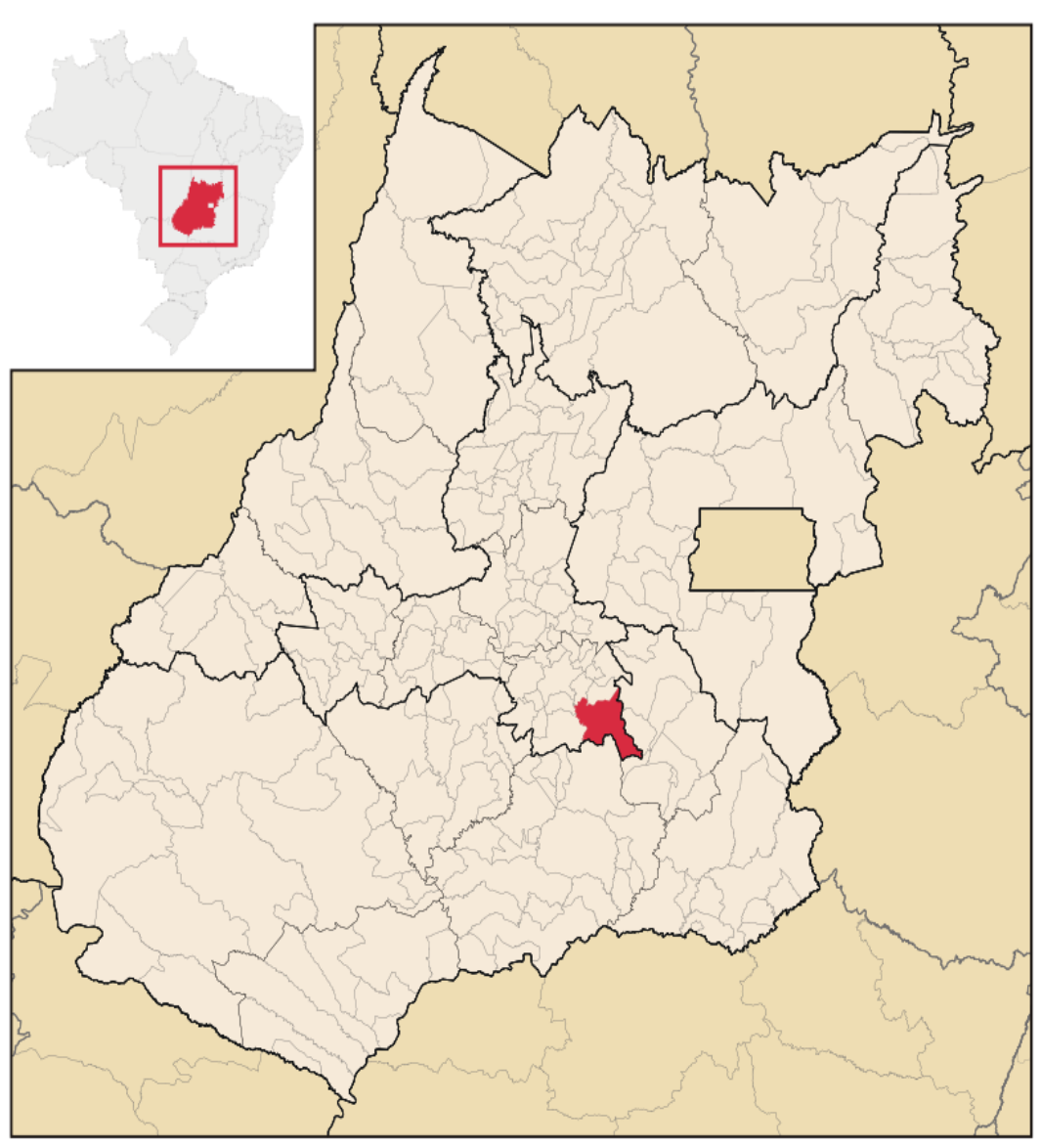

(Foto: Raphael Lorenzeto de Abreu)

A base econômica de Bela vista de Goiás sempre foi alicerçada pelas atividades agropecuárias. Durante muito tempo, a atividade de destaque foi o fumo cultivado e processado no município que foi principal produto de exportação durante décadas. Entretanto, atualmente uma grande quantidade dos proprietários de terra vivem das atividades agrícolas e pastoris. No município há também uma grande criação de gado leiteiro e gado de corte que vem atribuindo um relevante desenvolvimento na cidade.

O município em questão possui duas escolas públicas que oferecem o ensino médio para os alunos que moram na cidade e para os alunos que moram no campo: a Escola Estadual Dr. Belém e o Colégio Estadual Pedro Vieira Januário. A primeira oferta o 9ำ Ano do ensino fundamental no turno vespertino; o Programa de Fortalecimento do Ensino Noturno - PROFEN -, no turno noturno; e o ensino médio (1ํㅡㄹ $2^{\circ}$ Ano e $3^{\circ}$ Ano) em três turnos: matutino, vespertino e noturno. A segunda escola, o Colégio 
Estadual Pedro Vieira Januário, oferta apenas o ensino médio ( $1^{\circ}$ Ano, 2ํㅡㄹ Ano e $3^{\circ}$ Ano) em tempo integral, período diurno. A Escola Estadual Dr. Belém no respectivo ano de 2017, no segundo semestre, contava com um total de 494 alunos matriculados no ensino médio distribuídos nos três turnos, 153 alunos matriculados no ensino fundamental e 47 matriculados no PROFEN. O Colégio Estadual Pedro Vieira Januário, nesse mesmo período, contava com um total 165 alunos que cursam o ensino médio em período integral.

Para o desenvolvimento da pesquisa estão sendo considerados os alunos do Colégio Estadual Pedro Vieira Januário, que cursam o ensino médio em tempo integral. A restrição da pesquisa somente aos alunos dessa instituição se justifica pelo fato de ser uma modalidade relativamente nova à realidade do município, nunca houve na história da cidade, uma escola nesse formato. Sendo uma novidade em nosso cenário, a pesquisa objetiva discutir a realidade do jovem que mora no campo e que precisa dedicar todo seu tempo diurno às atividades escolares na cidade. Várias questões permeiam essa discussão, como: esse jovem trabalha de alguma forma na propriedade rural ou se dedica integralmente aos estudos? O seu momento de lazer é realizado na cidade ou no campo? Sua família é de uma tradição camponesa? Que profissão deseja ter no futuro? Ele pretende algum dia migrar definitivamente para cidade? Como é a vida no campo se tratando de questões econômicas? Segurança? Saúde? As respostas dessas perguntas nortearão o trabalho, na tentativa de compreender se a juventude rural do município anseia um modo de vida diferente de seu atual estado.

No entanto, o primeiro momento, o acesso à algumas informações foi bastante restrito, o que faz com que a pesquisa apresente dados ainda incipientes, pois serão melhores analisados ao longo do processo de pesquisa.

No Colégio Estadual Pedro Vieira Januário, como já foi dito anteriormente, estão matriculados 165 alunos que cursam o ensino médio em período integral. A partir deste total de alunos, e das informações que foram acessíveis, a pesquisa se preocupou em estabelecer a relação dos alunos que residem na cidade, aqueles que residem no perímetro urbano, e os alunos que residem na zona rural, que residem no perímetro rural. Segue o gráfico. 


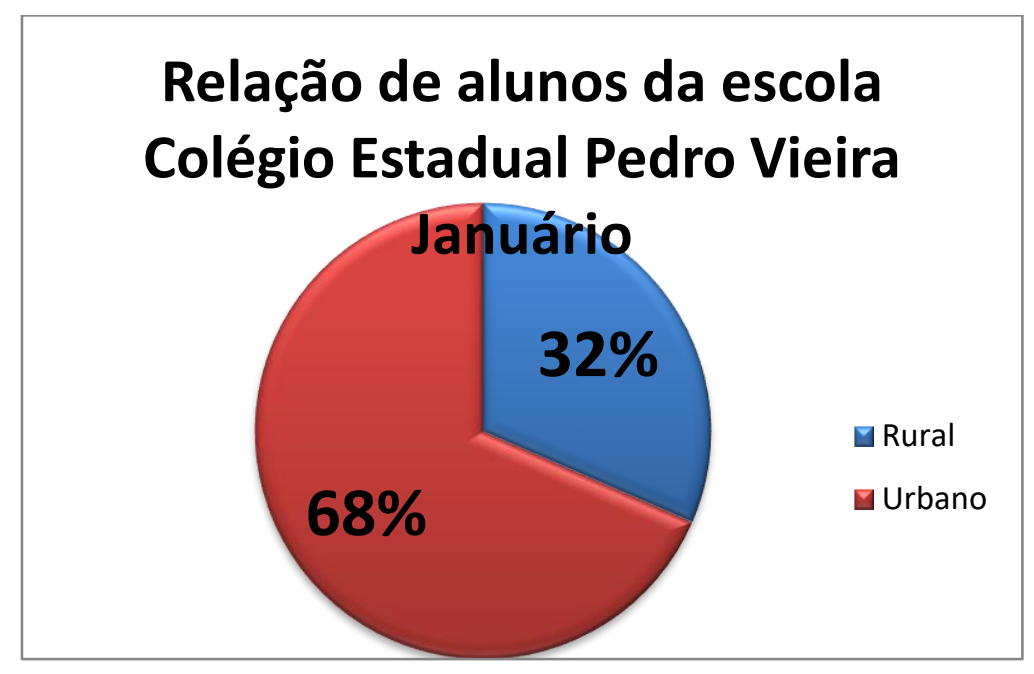

O gráfico mostra que a maioria dos estudantes desta instituição residem no perímetro urbano do município de Bela Vista de Goiás, no entanto, a quantidade de alunos que residem na zona rural apresenta um índice considerável. Dos 165 alunos da escola, 113 alunos são do perímetro urbano e 52 alunos do perímetro rural, ou seja, representam respectivamente, $68 \%$ e $32 \%$ do total de alunos. Outra distinção possível foi a distribuição por sexo (feminino e masculino) dos alunos estudantes do perímetro rural.

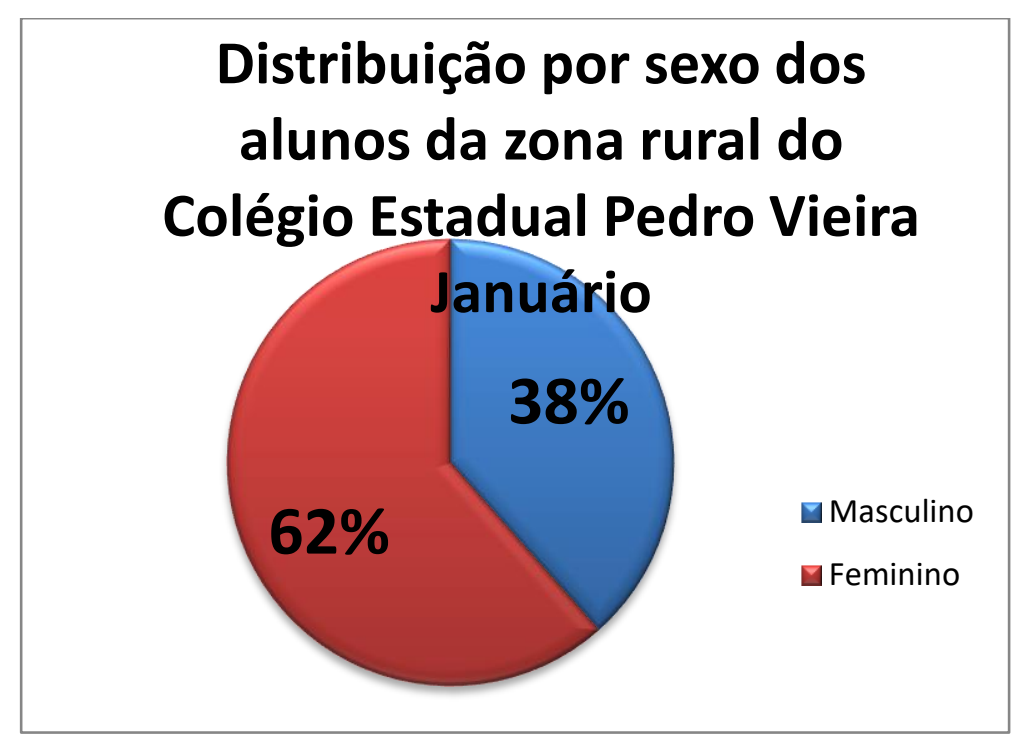


Do total de 52 alunos que residem na zona rural, 32 alunos se identificam como sendo do sexo feminino, que representam $38 \%$ do total, e 20 alunos se identificam como sendo do sexo masculino, que representam $62 \%$ do total. Essa informação também é importante para posteriormente aprofundarmos esse debate no que diz respeito à questão do gênero.

\subsection{DILEMAS E PERSPECTIVAS DA JUVENTUDE RURAL NA CONTEMPORANEIDADE}

Embora essa discussão seja pertinente ao nosso tempo, em outros séculos formularam-se indagações a respeito. Através do advento do capitalismo, a classe dos agricultores sofreu profundas transformações. Durante todo esse tempo, devido a tantas mudanças na estrutura política, econômica e social, essa categoria tem apresentado certa incapacidade de se estabelecer nesse sistema subordinado ao capital. Karl Marx em sua análise e teoria histórica antecipou o questionamento sobre a vida rural e seus desdobramentos. Nessa perspectiva, autores com a abordagem marxista apontam:

O capitalismo tomou a terra um bem de capital; pôs fim à propriedade
comunitária; transformou a produção urbana e agrícola em valores-de-troca;
fez do mercado translocal o locus privilegiado da vida socioeconômica; atraiu
trabalhadores para o centro urbano em busca de empregos; efetivou a
produção de mercadorias em larga escala; expulsou do campo famílias inteiras.
Tudo isso culminou na separação dos produtores diretos (artesãos e pequenos
agricultores) de seus meios de produção, ao convertê-los, tão somente, em
proprietários apenas de sua força de trabalho, enquanto etapa elementar para
a geração da mais-valia. Neste sentido, a cada progresso da economia de
mercado ocorria uma intensa fragilizaçãa da economia campesina, que
anteriormente bastava a si mesma. (RAMALHO; MOREIRA, S/D, p. 188-189)

No entanto, os dados demográficos sobre a população brasileira demonstram a continuidade do processo migratório campo-cidade nas últimas décadas. $\mathrm{Na}$ década de 70 a população rural do Brasil tinha aproximadamente 41 milhões de habitantes. Já a década de 80 essa população passou para 38,5 milhões, e na década de 90 essa população rural chegou a atingir 33,8 milhões de habitantes, isso corresponde a uma participação de $44,1 \%, 32,4 \%$ e $22 \%$ da população total do país, respectivamente. Quanto aos jovens brasileiros, na faixa etária de $15 \mathrm{a}$ 24 anos somam 34,1 milhões de pessoas, correspondendo a $20,1 \%$ do total da população; em áreas rurais vivem 5,9 milhões de jovens (IBGE, 2006 e 2010). 
No que diz respeito a Goiás, a população total é representada por 6.003 .788 habitantes, dentre estes a população urbana total corresponde a 5.420 .714 habitantes e a população rural total 583.074 habitantes, sendo 317.441 homens e 265.633 mulheres (IBGE, 2010). Sobre o número de estabelecimentos rurais familiares e não familiares, é possível verificar que em Goiás apenas 65\% dos estabelecimentos são de produtores familiares, enquanto $35 \%$ são de produtores não familiares. Em relação a participação do valor da produção agropecuária apenas $16 \%$ do valor da produção provêm da agricultura familiar, e $84 \%$ é gerado pela agricultura não familiar. Desse modo, fica evidente que a produção da agricultura familiar tem menor valor agregado do que aquilo que é produzido pela agricultura não familiar, ou seja, pelos grandes proprietários de terra, os latifundiários (XAVIER, 2012).

Dados como esses demonstram que cada vez mais, especialmente os jovens, trocam o campo pela cidade. Umas das justificativas para isso é que quando o jovem passa a ter maiores responsabilidades dentro da propriedade rural, em relação aos deveres como agricultor seja ele produtivo, econômico ou social, ele passa a visualizar e sentir as dificuldades que a agricultura familiar tem encontrado ao longo dos anos, em relação à dificuldade de crédito, assistência técnica, investimento em tecnologia, etc.. A partir do momento que ele se envolve com esses problemas, o seu desenvolvimento pessoal se torna mais difícil, pois é nessa fase da vida que eles estão planejando a realização de seus projetos pessoais que muitas vezes são interrompidos pelas condições que o núcleo familiar se encontra (SPANEVELLO e VELA, 2003).

Os fatores que motivam a emigração rural estão divididos entre os atrativos da vida rural (que são fatores de atração) e as dificuldades da vida no meio rural e da atividade agrícola (que são os fatores de expulsão) (BRUMER, 2007). De acordo com Brumer (2007: p.3)

Apesar do peso dos fatores estruturais, as decisões sobre a migração são tomadas por indivíduos, que variam na avaliação de fatores de atração ou de expulsão. Ademais, na decisão de migrar, provavelmente os fatores de expulsão são anteriores aos de atração, na medida em que os indivíduos fazem um balanço entre $s$ situação vivida e a expectativa sobre a nova situação. Dependendo de como se examina a questão, os estudos sobre a migração dos jovens focalizam ora os atrativos no novo ambiente ora os aspectos vistos como negativos no local de origem. Entre os "ruralistas" 
predominam as análises que apontam ante os fatores de expulsão do que os de atração, como causas de migração.

Além disso, o histórico de ausência de políticas públicas no Brasil, a dificuldade e insuficiência dos serviços de saúde e de educação de boa qualidade, bem como o acesso ao lazer tem reduzido a vontade dos jovens permanecerem vivendo na zona rural. A falta de apoio para a criação de alternativas de trabalho e meios diversificados para a composição de renda aumenta mais ainda a tendência dos jovens deixarem o campo, que muitas vezes são incentivados até pelos próprios pais por acreditarem que na cidade terão todas as oportunidades para a concretização dos seus sonhos (SILVA, 2006).

De modo geral, a baixa educação e a insuficiência de políticas públicas têm gerado vários problemas, entre os quais se pode fazer referência ao analfabetismo; grande número de crianças e jovens fora da escola; a carência de ensino rural; não valorização e formação de docentes; docentes alheios à realidade rural; abandono da escola rural; ausência de infraestrutura adequada; carência de renovação pedagógica; escolas deslocadas das necessidades e das questões do mundo real e alheia aos interesses dos trabalhadores rurais, de seus movimentos e organizações, e assim estimuladora do abandono do campo.

É importante observar que para cursar o ensino médio, em geral, o jovem rural precisa ir para as sedes dos seus municípios regularmente, onde terão acesso á outra forma de vida e diferentes modos de relacionamento social ao qual começarão a confrontar os valores da vida no campo e na cidade e despertarão o desejo de viver tal modo de vida diferente do qual foram criados (SIQUEIRA, 2004).

Outro fator apontado em outras pesquisas sobre jovens rurais é a predominância de homens no campo, pois a maior parte dos emigrantes são moças, levando à respectiva masculinização do campo. A situação mais delicada das mulheres deriva da desvalorização das atividades realizadas por elas, por serem trabalhos mais leves que são considerados como uma "ajuda", isso as torna pouco visíveis (PAULILO, 2004) e também pelo pouco espaço a elas reservado na atividade agrícola, onde atuam apenas como auxiliares (BRUMER, 2007). Essas situações fazem com que ocorra o desinteresse por parte das mulheres na continuidade da vida no campo, que acabam buscando os centros urbanos em busca de trabalho remunerado e conhecimento, bem como uma melhoria de vida. Muitas vezes são até 
mesmo incentivadas pelos próprios pais a procurarem os centros urbanos por acreditarem que terão mais oportunidades de trabalho e não precisarão trabalhar no "pesado". Essa predominância de mulheres migrando para cidade não está ligada a condições favoráveis para esse gênero no mercado de trabalho urbano, mas sim a desvalorização do seu trabalho no campo e a falta de perspectivas que elas encontram (ABRAMOVAY, 1998).

Um aspecto que vem sendo abordado ultimamente como sendo um fator para o êxodo rural é a falta de espaços que tragam cultura e lazer para o campo, pois são fatores de descontração e socialização que aliviam o estresse causado pelo desgaste do dia-a-dia de trabalho no campo, assim como a ansiedade e depressão. Assim, os jovens rurais procuram na cidade a realização dessas atividades de cultura e lazer (festas, prática de esportes, cinema, etc.), já que o campo é tido como um lugar de tranquilidade de descanso (CARNEIRO, 1998). De acordo com Carneiro (1998: p. 257), "a ausência de espaços de lazer é responsável, entre outros fatores, pela avaliação negativa do campo em relação à cidade e pelo desejo de migração".

Geralmente, o jovem rural começa a trabalhar no campo por volta dos 10 a 12 anos de idade, realizando algumas atividades mais simples, e por volta dos 16 ou 17 anos muitas vezes já assume o papel de adulto na propriedade, eles acabam perdendo um pouco da vivência da adolescência no que diz respeito a atividades como lazer e recreação para assumir as responsabilidades a eles transferidas (OLIVEIRA, 2006).

Para além destas questões, propomos um diálogo no sentido de discutir a juventude rural como categoria invisibilidade e, consequentemente, como uma categoria estigmatizada. Antes

de tudo, é importante considerar que a invisibilidade aqui se refere a situações em que determinados sujeitos se encontram imperceptíveis nas relações sociais. Trata-se de uma ação social que implica em não ver o outro, não enxergar sua existência social. Essa invisibilidade nega ao outro o direito ao reconhecimento e à identidade social. Entre tantos excluídos e marginalizados de nossa sociedade atual, os jovens rurais também estão presentes. A invisibilidade social a que estes jovens estão submetidos consiste numas das expressões de exclusão social, inviabilizando, sobretudo, sua própria condição de existência de direitos sociais. 
De acordo com Carneiro e Castro (2007), uma questão central para a invisibilidade são as posições distintas entre "mundo rural" e "mundo urbano" em nossa sociedade. A análise da categoria juventude rural revela como essa hierarquia entre "mundo rural" e "mundo urbano" permanece e opera no cotidiano das pessoas. Esta ainda é umas das questões que mais aparecem em entrevistas com jovens rurais. Quem se identifica como jovem rural sente cotidianamente o estigma de viver no campo.

De modo geral, os jovens rurais estão ligados ao conservadorismo, atrelado ao passado e ao tradicional, muitas vezes considerados alienados, marcados pela agricultura e exploração da natureza, bem diferente dos jovens urbanos, atrelados à modernidade e ao futuro e marcados pela urbanização e industrialização. Essa dicotomia rural-urbana, gera uma concepção negativa e estigmatizante dos jovens do meio rural, associados ao atraso e ao isolamento e fadados ao desaparecimento diante da tendência crescente da urbanização do país.

\section{CONSIDERAÇÕES FINAIS}

O jovem do campo, assim como afirmou Abramo (2005), ainda é um sujeito difícil de ser discutido, tendo em vista sua complexidade cultural e sua pouca representatividade nas pesquisas no que concerne a suas dinâmicas culturais e sociais. Contudo, ao discutirmos sobre os jovens rurais estudantes do município de Bela Vista de Goiás, podemos perceber as desigualdades desse jovem da contemporaneidade. $\mathrm{O}$ fato de ser jovem e de morar em área rural, o torna um indivíduo com dilemas e perspectivas distintas, as quais muitas vezes est relacionadas ao modo de ver e viver a vida.

Compreendemos que os jovens vivenciam diferentes contextos em seu cotidiano, alguns comuns a outros jovens, outros específicos aos seus espaços de vivência. Os jovens do campo, singularmente, são indivíduos que vivenciam a dinâmica relação entre campo e cidade e são influenciados constantemente por esta. Por isso, procuramos compreendê-los enquanto indivíduos ativos que, em situações plurais, fortificam e produzem aquilo que é expresso em sua identidade. 
A análise do jovem do campo e suas concepções de rural e urbano não se esgotam nas discussões realizadas nesta pesquisa, uma vez que surgem novos olhares e diferentes aspectos de análise. Assim, é importante dizermos que, com esse estudo, esperamos contribuir e despertar ainda mais olhares para investigações relacionados às juventudes, em especial, para os jovens do campo e suas práticas socioculturais que se configuram, cada dia mais, como um importante elemento de análise.

\section{REFERÊNCIAS BIBLIOGRÁFICAS}

ABRAMO, H. W. Condição juvenil no Brasil contemporâneo. In: ABRAMO, H. W.; BRANCO, P. P. M. Retratos da juventude brasileira: análises de uma pesquisa nacional. São Paulo: Instituto Cidadania; Fundação Perseu Abramo, 2005.

ABRAMOVAY, Ricardo. (Coord.) Juventude e agricultura familiar: desafios dos novos padrões sucessórios. Brasília, Unesco, p. 121-140, 1998.

BOURDIEU, Pierre. A "juventude" é apenas uma palavra! Questões de sociologia. Rio de Janeiro: Marco Zero. p. 112-121, 1983.

BRUMER, Anita. A problemática dos jovens rurais na pós-modernidade. In: CARNEIRO, Maria José; CASTRO, Elisa Guaraná de. Juventude rural em perspectiva. Rio de Janeiro: Mauad, p.35-51, 2007.

CARNEIRO, Maria José. CASTRO, Elisa Guaraná de. Juventude Rural em perspectiva. Ed. Editora Mauad, 2007.

CARNEIRO, Maria José. Ruralidade: novas identidades em construção. Estudos Sociedade e Agricultura, n.11, Rio de Janeiro: CPDA/UFRRJ, p. 160-257, 1998.

CASTRO, G.C.; MAÍRA, M.; ALMEIDA, S.L.F. RODRIGUES. M.E.B.; CARVALH J.G.C.; Os jovens estão indo embora? Juventude rural e a construção de um atoı político. Editora Mauad. 2009.

CENSO AGROPECUÁRIO $2006 . \quad$ Disponível em: http://www.ibge.gov.br/home/estatistica/economia/agropecuaria/censoagro/ Acesso em: 13 de Janeiro de 2018.

CENSO DEMOGRÁFICO 2010. Disponível em: http://censo2010.ibge.gov.br/ Acesso em 03 de Janeiro de 2018.

COIMBRA, C.; BOCCO, F.; NASCIMENTO, M. Subvertendo o conceito de adolescência. Arquivos Brasileiros de Psicologia, v. 57, n. 1. p. 2-11, 2005. 
DAYRELL, J.T.; GOMES, N.L. A juventude no Brasil. Disponível em: <www.fae.ufmg.br/objuventude/textos/SESI>. Acesso em: 28 Janeiro de 2018.

FROSSARD, Antônio Carlos. Identidade do Jovem rural confrontando com estereótipo de Jeca Tatu. Um estudo qualitativo com os jovens da EFA Rei Alberto I. Dissertação de Mestrado - Faculdade de Ciências e Tecnologias da Educação. Universidade Nova de Lisboa. Portugal. Nova Friburgo. RJ. 2003.

GUILHOTO, J. J. M. ; ICHIHARA, S. M. ; SILVEIRA, F. G. ; AZZONI, C. R. Agricultura Familiar: contribuindo para a riqueza nacional. Marco Social (Rio de Janeiro), v. 9, p. 20-25, 2007.

INSTITUTO BRASILEIRO DE GEOGRAFIA E ESTATÍSTICA (IBGE) 2016 Disponível em: http://ibge.gov.br/home/estatistica/populacao/estimativa2015/default.shtm Acesso em: 12 de Dezembro de 2017.

LAMARCHE, Hugues. A agricultura familiar, comparação internacional: uma realidade multiforme. Campinas, São Paulo, Editora Unicamp, p. 19-36, 1993.

LOURENZANI, Wagner Luiz. Captação gerencial de agricultores familiares: uma proposta metodológica de extensão rural. Organizações Rurais e Agroindustriais/Revista de Administração da UFLA, Lavras, volume 8 - Set/Dez, p. 313-322, 2006.

NOVAES, Regina. Juventude/juventudes? Em comunicações ISER, (50), ano 17, Rio de Janeiro: ISER, 1998.

OLIVEIRA, Edmar Geraldo. O lazer e a melhoria da qualidade de vida dos jovens rurais de São João Evangelista - MG, 2006. Dissertação (Mestrado em Meio Ambiente e Sustentabilidade). Centro Universitário de Caratinga. Caratinga: UNEC.

PAULILO, Maria Ignez. Trabalho familiar: uma categoria esquecida de análise. Florianópolis, p.52-229, 2004.

PREDIGER, Solange. Estado da Arte da Situação do Jovem rural: a construção de identidades. Revista Anagrama: Revista Cientifica Interdisciplinar da Graduação. Ano 3. Ed. 1 Setembro/Novembro de 2009.

RAMALHO, C.W.N.; MOREIRA, R.N.P.; A visão escatológica de Marx e Engels sobre o campesinato e a vida local rural. Estudos de Sociologia. Rev, do Progr. de PósGraduação em Sociologia da UFPE, v. 16, n. I, p. 179- 208, S/D.

SILVA, P. S.; FILHO, E. T. D.; MARACAJÁ, V. P. B. B.; MARACAJÁ, P. B. ; PEREIRA, T. F. C. Agricultura Familiar: Um Estudo Sobre a Juventude Rural no Município de Serra do Mel - RN. Revista Verde (Mossoró - RN - Brasil) v.1, n.1, p. 54-66, 2006. 


\section{REFERÊNCIAS FILMOGRÁFICAS}

Opinião Pública. Direção: Arnaldo Jabor. Brasil: 1967 [produção].(65 min.)

As sementes. Direção: Beto Novaes. Brasil: 2015 [produção]. (30 min.) 